\title{
Microbial contamination of medications used to treat glaucoma
}

\author{
Orna Geyer, Edward J Bottone, Steven M Podos, Robert A Schumer, Penny A Asbell
}

\begin{abstract}
Aims-A study was conducted to estimate the frequency of contamination of topical antiglaucoma medications used by asymptomatic patients.

Methods-The drops and the bottle tips of 194 in use topical medications and the conjunctiva from 109 treated glaucoma patients were cultured.

Results-Bacteria were recovered from $55(28 \%)$ medications. The bottle tip was more frequently contaminated than the drops $(\mathbf{p}=0.008)$. Gram positive organisms were cultured from $50(91 \%)$ of 55 contaminated medications. Thirteen patients $(12 \%)$ had the same microorganism recovered from the conjunctiva and from the contaminated medication. The frequency of contamination of medications increased with increasing duration of use. Bacterial contamination occurred in $19 \%$ of eyedrops less than 8 weeks old in contrast with $40 \%$ of bottles used for more than 8 weeks.

Conclusion-Our data suggest that ocular medications to treat glaucoma frequently become contaminated with bacteria and that contamination is related to duration of use. We therefore recommend that opened topical antiglaucoma eyedrops should be replaced on a regular basis.

(Br f Ophthalmol 1995; 79: 376-379)
\end{abstract}

The use of contaminated eyedrops and their containers may give rise to serious ocular infections. In most cases of glaucoma, topically applied antiglaucoma agents constitute the first line of therapy as well as being the most frequently used medications. Eyedrops contaminated with bacteria that are used for glaucoma treatment have been implicated in ocular infections. ${ }^{12}$ Templeton and associates $^{1}$ described three cases of Serratia marcescens keratitis after keratoplasty. The same bacterial species was recovered from the outer grooves of in use bottle tops, but not from the eyedrop solutions (timolol, prednisolone). Schein et $a l^{2}$ reported seven cases of severe Gram negative bacterial keratitis associated with the use of contaminated topical medications. Timolol maleate was implicated in most of these cases.

We conducted a study to estimate the frequency of microbial contamination of topical antiglaucoma medications used by asymptomatic patients. Simultaneously, we cultured the eyes of these individuals and correlated these findings with the micro-organisms cultured from their medications.

\section{Materials and methods}

PATIENTS

A total of 109 consecutive glaucoma patients using topically applied ocular medications were recruited from the private glaucoma service and the glaucoma clinic of the Mount Sinai Hospital, New York, from May to October 1992. Sixty two consecutive agematched controls with normal eyes, who were not using any topical ocular medications, were recruited from the private service and general eye clinic during the same period. We included patients who had established a routine pattern of care and excluded patients who had used ocular medications for less than 3 months and/or who had evidence of ocular infection or failed to bring to the visit all in use ocular medications. History obtained included the length of time the eyedrops were in use and the method of administration - for example, whether contact was made with eyelid as patients instilled their own eyedrops. The study protocol was approved by the human subjects committee at Mount Sinai Medical Center and informed consent was obtained from all patients.

\section{CONJUNCTIVAL CULTURES}

Conjunctival specimens were obtained by passing a sterile bacteriological $(0.001 \mathrm{ml})$ loop across the inferior conjunctival cul de sac. The specimen was immediately inoculated onto two chocolate agar plates. One was placed at $37^{\circ} \mathrm{C}$ in ambient air and the other under anaerobiosis (Gaspak). Plates were examined after 48 hours of incubation for growth. A positive culture was taken as one that grew one or more colonies. Isolates were characterised by standard criteria. ${ }^{3}$

\section{MEDICATION MICROBIOLOGY}

Medications for microbial assessment were cultured initially by touch inoculating two chocolate agar plates with the tip of the medication bottle. Afterwards, the tip was cleaned with $95 \%$ alcohol, the bottle shaken, and several drops $(\simeq 0.005 \mathrm{ml})$ were allowed to impinge on the agar surface. One plate was incubated at $37^{\circ} \mathrm{C}$ under aerobic and the other under anaerobic conditions, respectively, and evaluated for growth after 48 hours' incubation.

STATISTICAL METHODS

The unpaired $t$ test was used to compare

Mount Sinai School of
Medicine, New York,
USA
Department of
Ophthalmology
O Geyer
S M Podos
R A Schumer
P A Asbell
Department of
Medicine Infectious
Diseases
E J Bottone
Correspondence to:
Steven M Podos, MD,
Department of
Ophthalmology, Mount Sinai
School of Medicine, Box
1183, One Gustave L Levy
Place, New York, NY
10029-6574, USA.
Accepted for publication
9 December 1994


Table 1 Patient characteristics

\begin{tabular}{llll}
\hline & Glaucoma & Control & Total \\
\hline Age (years) & & & \\
Mean & $68 \cdot 1$ & $59 \cdot 6$ & $65 \cdot 1$ \\
SD & $11 \cdot 2$ & $16 \cdot 8$ & $14 \cdot 5$ \\
Sex (M/F) & $43 / 66$ & $23 / 39$ & $66 / 105$ \\
Race & & 37 & 120 \\
White & 83 & 15 & 31 \\
Black & 16 & 10 & 20 \\
Other & 10 & 62 & 171 \\
Total & 109 & & \\
\hline
\end{tabular}

Table 2 Distribution of micro-organisms cultured from conjunctiva of glaucoma and control groups

\begin{tabular}{lcc}
\hline & Glaucoma & Control \\
& No (\%) & No (\%) \\
\hline No growth & $77(71)$ & $45(73)$ \\
Usual conjunctival flora* & $29(26)$ & $14(22)$ \\
Potential pathogenst & $3(3)$ & $3(5)$ \\
Total & 109 & 62 \\
\hline
\end{tabular}

*Coagulase-negative staphylococci, diphtheroids,

Propionibacterium acnes, Streptococcus viridans.

†Proteus mirabilis, Capnocytophaga spp, Haemophilus influenzae.

continuous variables. Proportions were compared by $\chi^{2}$ statistics.

\section{Results}

STUDY POPULATION

The study group consisted of 171 patients, 109 being treated for glaucoma and 62 normal controls. The characteristics of the study population are given in Table 1 . None of the glaucoma patients or controls had a concurrent ocular external finding.

\section{CONJUNCTIVAL CULTURE}

Of 171 patients enrolled in the study, 49 patients $(29 \%)$ had a positive conjunctival culture for a bacterial species from at least one eye. There was no statistically significant $(\mathrm{p}=0 \cdot 1)$ difference between glaucoma patients $(30 \%)$ and normal controls (28\%). Staphylococcus epidermidis was the most frequent contaminant, $17 \%$. The same organism was cultured from both eyes in 21 (43\% of the patients with positive growth) patients (Table 2).

\section{MEDICATIONS}

One hundred and nine patients with glaucoma used a total of 194 medications. Benzalkonium chloride 0.014 was the preservative in all medications. Fifty two patients used a single medication, 29 patients used two medications, and 28 patients used three or more medications.
Table 4 Distribution of bacterial species cultured from in use medications

\begin{tabular}{ll}
\hline & Tip +drop (n=55) \\
Species isolated & No (\%) \\
\hline Gram positive & \\
Staphylococcus epidermidis & $38(69)$ \\
Staphylococcus aureus & $6(11)$ \\
Streptococcus viridans & $1(2)$ \\
Propionibacterium acnes & $2(4)$ \\
Corynebacterium spp & $3(5)$ \\
Gram negative & $1(2)$ \\
Moraxella species & $2(2)$ \\
Enterobacter aerogenes & $6(11)$ \\
Serratia marcescens & $1(2)$ \\
Flavobacterium spp & $1(2)$ \\
Pseudomonas spp & $1(2)$ \\
Proteus mirabilis & \\
\hline${ }^{\alpha}$ Haemolytic streptococci. &
\end{tabular}

MEDICATION CONTAMINATION

Fifty five $(28 \%)$ medications had microorganisms cultured from at least one site. There was no statistically significant difference $(p=0.3440)$ between the contamination rate of the different medications. The bottle tip was more frequently contaminated than the drops $(p=0.0008)$ (Table 3$)$. Gram positive organisms were cultured from $91 \%$ of 55 contaminated medications and were more likely isolated from the bottle tip $(p=0.0075)$ (Table 4). Gram negative organisms tended to be isolated from both the tip and medication solution. Thirty four $(31 \%)$ patients with glaucoma had at least one medication contaminated at one or more sites (tip, drop). Thirteen $(38 \%)$ of them had the same organism (Staphylococcus epidermidis) cultured from the conjunctiva to which the contaminated medication was applied (concordant contamination), and they belonged only to the private group. Interestingly, none of the potentially pathogenic species (Serratia marcescens, Moraxella species) isolated from the medications were found on the conjunctiva to which that medication was applied. There was a statistically significant difference $(p=0.022)$ between the age of patients whose drops were contaminated $(71.25$ (SD 1.21)) and those whose drops were not $(66 \cdot 88$ (SD. 1.42)).

\section{PATIENT INTERVIEW}

Thirty seven patients with glaucoma touched their eyes during medication installations. All had at least one contaminated medication. However, only one of six patients whose medication revealed a potential pathogen (Serratia marcescens) touched the lid during medication application.

There was a clearcut association between length of time a medication was in use and bacterial contamination (Table 5). Bacterial contamination occurred in $20(19 \%)$ bottles

Table 5 Correlation between medication contamination and length of time used

\begin{tabular}{lccl}
\hline Medication & $\begin{array}{l}\text { Tip contaminated/ } \\
\text { total (\%) }\end{array}$ & $\begin{array}{l}\text { Drop contaminated/ } \\
\text { total (\%) }\end{array}$ & $\begin{array}{l}\text { Any site contaminated/ } \\
\text { total (\%) }\end{array}$ \\
\hline Miotics & $10 / 67(15)$ & $4 / 67(6)$ & $14 / 67(21)$ \\
$\beta$ Blockers & $20 / 75(27)$ & $8 / 75(11)$ & $28 / 75(38)$ \\
Sympathomimetics & $7 / 41(17)$ & $3 / 41(7)$ & $10 / 41(24)$ \\
Other & $2 / 11(18)$ & $1 / 11(9)$ & $3 / 11(27)$ \\
Total & $39 / 194(20)$ & $16 / 194(8)$ & $55 / 194(28)$ \\
\hline
\end{tabular}

^Steroids, antibiotics.

\begin{tabular}{lll}
\hline $\begin{array}{l}\text { Time in use } \\
\text { (weeks) }\end{array}$ & Tested & $\begin{array}{l}\text { Medications contaminated } \\
\text { No }(\%)\end{array}$ \\
\hline$<4$ & No & $20(19)$ \\
$5-8$ & 108 & $9(20)$ \\
$9-12$ & 44 & $7(41)$ \\
$>12$ & 17 & $10(40)$ \\
\hline
\end{tabular}


1-4 weeks old, nine (20\%) bottles 5-8 weeks old, and seven $(41 \%)$ bottles $9-12$ weeks old. In bottles more than 12 weeks old, there was a $40 \%$ contamination rate. There was a statistically significant $(p=0.0045)$ difference in the rate of bacterial contamination in drops used less than 8 weeks compared with those used over 8 weeks.

\section{Discussion}

Our data on 109 glaucoma patients suggest that a disturbingly high frequency $(28 \%$ of 194 bottles sampled) of microbial contamination is present in the eyedrops used by asymptomatic glaucoma patients. Past studies show conflicting views regarding the frequency of microbial contamination of eyedrops after their use. A high contamination rate was reported by Schein et $a l^{4}(29 \%)$ Marion and Tampert ${ }^{5}$ $(27 \%)$, and Hovding and Sjurjen $6(12 \cdot 9 \%)$.

Other studies showed a significantly lower rate of contamination. Stevens and Matheson, ${ }^{7}$ and Aslund et $a l^{8}$ reported $2 \cdot 3 \%$ and $2 \cdot 2 \%$ rate of eyedrops contaminated respectively. However, unlike our study, cultures were taken from bottles that had been used for eyedrop application by a nurse or a doctor given to different patients during a single session only. A low rate $(2 \cdot 5 \%)$ of bacterial contamination was also found by Hugo and Wilson. ${ }^{9}$ However, cultures were taken from the solution only. The culture positivity rate might have been increased by culturing the bottle tip as this seems to be the most frequently colonised site. ${ }^{14610}$

In our study, contamination was divided into that of the tip of the bottle, and that of the bottle contents. The tip of eyedrop bottles was more frequently $(\mathrm{p}<0.001)$ contaminated $(20 \%)$ than the bottle contents $(8 \%)$. This finding is comparable with that noted in earlier studies, 14610 suggesting that the moist nozzle may serve as a reservoir for microbial contamination, and during use the patient may inadvertently touch it to eyelids, and subsequently during storage, bacterial contaminants may transmigrate to the head space between the cap and the bottle top and contaminate the bottle contents. Gram positive organisms tended to be isolated from the tip, while Gram negative organisms tended to be isolated concurrently from both medication and tip sources. Schein and Hibberd ${ }^{4}$ suggested that the growth of Gram negative organisms is less likely to be inhibited by the medication preservatives. In that study thiomersal was the preservative present in all medications.

There is a strong evidence in our study that eyedrops get contaminated by contact with eyelids since: (1) the organisms responsible for frequent contamination were Staphylococcus epidermidis, Staphylococcus aureus, and Corynebacterium (diphtheroids) species, all of which comprise part of the resident skin and normal eye flora ${ }^{11} 12$; (2) the same organism was cultured from bottles of different medications from the same patient in one third of patients that used more than one medication;
(3) solution bottles that touched patient eyes during medication instillation were contaminated. Therefore, proper direction for administering ophthalmic solution should be given to patients to minimise the risk of microbial contamination. The age of patients was a potential risk factor since patients whose medications were contaminated were older, suggesting a possible reflection of their ability to properly instil eyedrops. In the present study, there is an extremely low incidence of bacterial colonisation of the conjunctiva $(30 \%)$ among the glaucoma and normal groups. Reports on the percentage of negative bacterial findings in normal conjunctiva range from $30 \%$ to $90 \% .^{11}{ }^{13-15}$ Nevertheless, the bacterial species isolated from conjunctival cultures of our patients are similar to those isolated from patients in other studies. ${ }^{11} 1214$ The differing incidence of culture positivity of the conjunctiva recorded in our study may be partially due to differences in procedures and microbiological methods rather than true differences in incidence. Our technique was to collect the specimen from the lower fornix with a sterile $0.001 \mathrm{ml}$ loop (rather than using a cotton swab), care being taken not to touch the edge of the eyelid.

The frequency of contaminated drops increased with duration of use in our study. Nineteen per cent of bottles $0-8$ weeks old were contaminated in contrast with $40 \%$ of bottles in use for more than 8 weeks. Marion and Tapert $^{5}$ and Hugo and Wilson ${ }^{9}$ also showed a relation between length of use and rate of microbial contamination. Hovding and Sjursen, ${ }^{7}$ on the other hand, claimed that the degree of contamination did not increase with length of use.

Secondary ocular infection is not a significant problem with topical ocular glaucoma therapy. However, eyedrops contaminated with bacteria that are used for glaucoma treatment have been implicated in ocular infections. ${ }^{12}$

Our data suggest that the contamination of eyedrops does occur with increased length of use of bottles. We, therefore, recommend that opened topical glaucoma preparations should be replaced on a regular basis. Since potential pathogens were not isolated from conjunctiva to which the contaminated drops were applied, it appears that antiglaucoma eye drops can usually be used safely by patients. However, when secondary surface conditions are present, such as abrasions and leaking filtering blebs, eyedrops could be the source of pathogens causing serious infections such as corneal ulcers or endophthalmitis. As medications were contaminated by all patients who touched their eyes during instillation, proper precautions and directions for administering and handling ophthalmic medications are necessary to minimise the risk of microbial contamination.

The manuscript was presented as a poster at the annual meeting of the American Academy of Ophthalmology, Chicago, 1993. Supported, in part, by grants EY01867, EY03651, EY05841, and EY05852 from the National Eye Institute, Bethesda, MD an unrestricted grant from Research to Prevent Blindness Inc New York, and a Castroviejo Foundation Fellowship awarded to Dr Orna Geyer. 
The authors do not have any commercial or proprietory interest in the drugs tested in this study. Dr Podos is a consultant to Allergan Inc, Irvine, CA, USA. Pharmos Corporation, New York, NY, and Alcon Laboratories Inc, Fort Worth, TX, USA.

The statistical analysis was undertaken by Yael Villa from the Department of Statistics, Tel Aviv University, Israel.

We would like to thank Drs A Bartolomei and Janet Serle for patient referrals for this study.

1 Templeton WC, Eiferman RA, Snyder JW, Melo JC, Raff MJ. Serratia keratitis transmitted by contaminated eyedroppers. Am 7 Ophthalmol 1982; 93: 723-6.

2 Schein OD, Wasson PJ, Boruchoff SA, Kenyon KR. Microbial keratitis associated with contaminated ocular medications. Am $\mathcal{F}$ Ophthalmol 1988; 105: 361-5.

3 D'Amato RF, Bottone EJ, Amsterdam DA. Substrate profile systems for the identification of bacteria and yeasts by rapid and automated approaches. In: Balows A, ed. Manual of clinical microbiology. 5th ed. Washington DC: Manual of clinical microbiology. 5th ed. Washington

American Society for Microbiology, 1991: 128-36.
4 Schein OD, Hibberd PL, Starck T, Bakez AS, Kenyon KR. Microbial contamination of in-use ocular medications. Arch Ophthalmol 1992; 110: 82-5.

5 Marion AD, Tamert MJ. Bacterial contamination of timolol in use by non-selected clinic population. Invest Ophthalmol Vis Sci (suppl). Philadelphia: Lippincott, 1986: 36.
6 Hovding G, Sjursen H. Bacterial contamination of drops and dropper tips of in-use multidose eye drop bottles. Acta Ophthalmol (Kbh) 1982; 60: 213.

7 Stevens JD, Matheson MM. Survey of the contamination of eyedrops of hospital inpatients and recommendations for the changing of current practice in eyedrop dispensing Br f Ophthalmol 1992; 76: 36-8.

8 Aslund B, Olson OT, Sandell E. Studies on in-use microbial contamination of eye drops. Acta Pharm Suec 1978; 15: 389-94.

9 Hugo WB, Wilson JV. A survey of in-use contamination of eye-drops. f Hosp Pharm 1970; 28: 258-62.

10 Coad CT, Osato MS, Wilhelmus KR. Bacterial contamination of eyedrops dispensers. Am f Ophthalmol 1984; 98: 548-51.

11 Perkins RE, Kundsin RB, Pratt MV, Abramsen I, Leibowitz HM. Bacteriology of normal and infected conjunctiva. f Clin Microbiol 1975; 1: 147-9.

12 Locatcher-Khorazo D, Seegal BC. Microbiology of the eye. St Louis: Mosby, 1972: 13-23.

13 Duke-Elder S. Diseases of the outer eye. In: Duke-Elder S, ed. System of ophthalmology. St Louis: Mosby, 1965; 8: Part 1, 141

14 Bachrach U, Gurevitch J, Landau J, Birnbaum D. The flora of the normal conjunctiva of healthy people in Israel. Acta Med Orient 1953; 12: 10-3.

15 McNatt J, Allen SD, Wilson LA, Dowell VR. Anaerobic flora of the normal human conjunctival sac. Arch Ophthalmol 1978; 96: 1448-50. 